Full Length Article

\title{
Phospholipase A1-based cross-reactivity among venoms of clinically relevant Hymenoptera from Neotropical and temperate regions
}

\author{
Amilcar Perez-Riverol ${ }^{\mathrm{a}}$, Luís Gustavo Romani Fernandes ${ }^{\mathrm{b}}$, Alexis Musacchio Lasa ${ }^{\mathrm{c}}$, \\ José Roberto Aparecido dos Santos-Pinto ${ }^{\mathrm{d}}$, Débora Moitinho Abram ${ }^{\mathrm{b}}$, \\ Gabriel Hideki Izuka Moraes ${ }^{\mathrm{a}}$, Frederic Jabs ${ }^{\mathrm{e}}$, Michaela Miehe ${ }^{\mathrm{e}}$, Henning Seismman ${ }^{\mathrm{f}}$, \\ Mario Sergio Palma ${ }^{\mathrm{d}}$, Ricardo de Lima Zollner ${ }^{\mathrm{c}}$, Edzard Spillner, ${ }^{\mathrm{e}, *}$ \\ Márcia Regina Brochetto-Braga ${ }^{\mathrm{a}, \mathrm{g}, * *}$
}

\footnotetext{
${ }^{a}$ Laboratório de Biologia Molecular de Artrópodes-LBMA-IBRC-UNESP (Univ Estadual Paulista), Av. 24-A, n_1515, CEP 13506-900, Bela Vista, Rio Claro, SP, Brazil ${ }^{\mathrm{b}}$ Laboratório de Imunologia Translacional, Faculdade de Ciências Médicas, FCM, Universidade Estadual de Campinas-UNICAMP, Rua Vital Brasil, $n$ _ 300, CEP 13083887, Cidade Universitária “Zeferino Vaz", Campinas, SP, Brazil

${ }^{\mathrm{c}}$ Center for Genetic Engineering and Biotechnology, Biomedical Research Division, System Biology Department, Ave. 31, e/158 and 190, P.O. Box 6162, Cubanacan, Playa, Havana 10600, Cuba

d Centro de Estudos de Insetos Sociais-CEIS-IBRC-UNESP (Univ Estadual Paulista), Av. 24-A, $n^{\circ} 1515$, CEP 13506-900, Bela Vista, Rio Claro, SP, Brazil

e Immunological Engineering, Department of Engineering, Aarhus University, Gustav Wieds Vej 10 DK-8000 Aarhus C, Denmark

${ }^{\mathrm{f}}$ Euroimmun AG, Seekamp 21, Lübeck, Germany

${ }^{g}$ Centro de Estudos de Venenos e Animais Peçonhentos-CEVAP (Univ Estadual Paulista), Rua José Barbosa de Barros, 1780, Fazenda Experimental Lageado, Botucatu 18610-307, SP, Brazil
}

\section{A R T I C L E I N F O}

\section{Keywords:}

Insect venom allergy

Phospholipase A1

Cross-reactivity

Sensitization

Molecular diagnosis

\begin{abstract}
A B S T R A C T
Molecular cross-reactivity caused by allergen homology or cross-reactive carbohydrate determinants (CCDs) is a major challenge for diagnosis and immunotherapy of insect venom allergy. Venom phospholipases A1 (PLA1s) are classical, mostly non-glycosylated wasp and ant allergens that provide diagnostic benefit for differentiation of genuine sensitizations from cross-reactivity. As CCD-free molecules, venom PLA1s are not causative for CCDbased cross-reactivity. Little is known however about the protein-based cross-reactivity of PLA1 within vespid species. Here, we address PLA1-based cross-reactivity among ten clinically relevant Hymenoptera venoms from Neotropical and temperate regions including Polybia paulista (paulistinha) venom and Vespula vulgaris (yellow jacket) venom. In order to evaluate cross-reactivity, sera of mice sensitized with recombinant PLA1 (rPoly p 1) from $P$. paulista wasp venom were used. Pronounced IgE and IgG based cross-reactivity was detected for wasp venoms regardless the geographical region of origin. The cross-reactivity correlated well with the identity of the primary sequence and 3-D models of PLA1 proteins. In contrast, these mice sera showed no reaction with honeybee (HBV) and fire ant venom. Furthermore, sera from patients monosensitized to HBV and fire ants did not recognize the rPoly $\mathrm{p} 1$ in immunoblotting. Our findings reveal the presence of conserved epitopes in the PLA1s from several clinically relevant wasps as major cause of PLA1-based in vitro cross-reactivity. These findings emphasize the limitations but also the potential of PLA1-based HVA diagnostics.
\end{abstract}

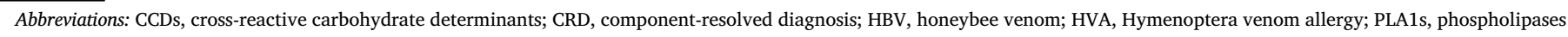
A1; Poly p 1, phospholipase A1 from Polybia paulista venom; PPV, P. paulista venom; vPLA1s, vespid phospholipases A1; YJV, yellow jacket venom

* Corresponding author.

** Corresponding author at: Laboratório de Biologia Molecular de Artrópodes-LBMA-IBRC-UNESP (Univ Estadual Paulista), Av. 24-A, n_1515, CEP 13506-900, Bela Vista, Rio Claro, SP, Brazil.

E-mail addresses: aperezriverol@gmail.com (A. Perez-Riverol), luisgrf1982@gmail.com (L.G.R. Fernandes), alexis.musacchio@cigb.edu.cu (A. Musacchio Lasa), jrbio04@rc.unesp.br (J.R.A. dos Santos-Pinto), deboramoitinhoabra@gmail.com (D. Moitinho Abram), gabriel.hideki@hotmail.com (G.H. Izuka Moraes), jabs@eng.au.dk (F. Jabs), miehe@eng.au.dk (M. Miehe), h.seismann@euroimmun.de (H. Seismman), mspalma@rc.unesp.br (M.S. Palma), zollner@unicamp.br (R. de Lima Zollner), e.spillner@eng.au.dk (E. Spillner), mrbbraga@rc.unesp.br (M.R. Brochetto-Braga). 


\section{Introduction}

Hymenoptera venom allergy (HVA) is one of the major causes of anaphylaxis worldwide ( $27 \%$ as compared to drugs and food with $41 \%$ and $20 \%$ respectively) (Oropeza et al., 2017). In untreated patients, insect stings can provoke IgE-mediated systemic reactions with potentially fatal outcome (Bilò, 2011). Identification of the primary sensitizing species is a critical prerequisite for venom immunotherapy (VIT), the only disease-curative treatment currently available. VIT is mostly well tolerated and reduces the risk of subsequent hypersensitivity reactions in the majority of the patients treated (Ollert and Blank, 2015).

HVA diagnosis is based on the patient's history along with skin tests and in vitro detection of specific IgE (sIgE) (Biló et al., 2005). Determination of sIgE however is significantly hampered by cross-reactivity. Up to $75 \%$ of double positivity to HBV and YJV are suggested to be caused by sIgE to CCDs (Müller et al., 2009), which are defined by an $\alpha 1$,3-fucose linked to the core glycan found on the majority of HBV and YJV allergens (Spillner et al., 2014). The production of CCD-free recombinant allergens such as vespid antigen $5 \mathrm{~s}$ and PLA1s or PLA2 from HBV using E. coli and Spodoptera frugiperda Sf9 cells significantly helped to overcome CCD-based cross-reactivity (Perez-Riverol et al., 2015; Seismann et al., 2010a; Frick et al., 2016; Köhler et al., 2014). Meanwhile, cross-reactivity due to common epitopes in homologous venom allergens remains a challenge for HVA diagnosis. The similarities of the allergen arsenal in the venom often prevent the speciesspecific differentiation of the culprit insect (Hoffman, 2008; Schiener et al., 2017). In Europe, protein-based cross-reactivity has particularly hindered the differentiation of YJV and Polistes (paper wasp) venom sensitizations (Caruso et al., 2007; Monsalve et al., 2012; Schiener et al., 2017). Species of the Polistinae subfamily have gained interest as they represent a major cause of wasp allergy in some geographical regions and are increasingly spreading to other moderate climate zones. Thus, characterization of allergens and protein-based cross-reactivity is mandatory to increase the specificity of the diagnosis.

In contrast to Europe, a broad diversity of clinically relevant insects has been described for Neotropical regions. Brazilian species (Fig. 1, Supplementary data Fig. 1) comprise $33 \%$ of the currently identified wasp species worldwide (Locher et al., 2014). In Brazil, members of Polistinae subfamily have been also reported as the major cause of sting accidents and insect-related anaphylaxis (Perez-Riverol et al., 2017). The venom composition of these Hymenoptera however has been poorly characterized and recombinant venom allergens from endemic species are not available for routine diagnosis (Bazon, 2017; PerezRiverol et al., 2016). Therefore, diagnostics are usually based on noncommercial crude venoms or reagents from Northern Hemisphere species like Vespula vulgaris (Perez-Riverol et al., 2017). The use of such material for diagnosis is associated with low sensitivity, high levels of CCD or peptide-based cross-reactivity and thus unreliable characterization of the patients sensitization profile.

To date, mainly the species-specific marker allergens antigen 5 (Ves v 5) and PLA1 (Ves v 1) from YJV as well as PLA2 (Api m 1) from HBV have been established for the differentiation of genuine sensitization to HBV and YJV (Korošec et al., 2012; Monsalve et al., 2012; Seismann et al., 2010b). Differentiation of wasp allergic patients however remains challenging. Venom PLA1s have been proven valuable tools as they allow the detection of sensitization in patients with negative sIgE to antigen 5 (Ebo et al., 2012; Korošec et al., 2012; Seismann et al., 2010b; Sturm et al., 2010). Moreover, the lower identity among wasp venom PLA1s as compared to antigens 5 (Monsalve et al., 2012; Schiener et al., 2017) renders PLA1s promising tools for identification of culprit species.

Here, we analyzed the PLA1-based cross-reactivity of venoms from eight Hymenoptera of clinical relevance in South America and two of their European counterparts. Our results suggest that PLA1s might be useful indicator allergens for differential sIgE diagnosis of vespid venom allergy within Neotropical regions and as marker allergens for differentiation of sensitization to wasp/honeybee and wasp/ant venoms.

\section{Materials and methods}

\subsection{Allergic patients' sera}

Sera from allergic patients monosensitized to $P$. paulista $(n=4)$, honeybee $(n=12)$ or fire ant $(n=4)$ venom and previously diagnosed by ELISA or ImmunoCAP 250 (Phadia, Upsala, Sweden), regardless sex or age, were obtained from the Ambulatório de Anafilaxia of the Hospital das Clínicas (Universidade Estadual de Campinas-UNICAMP,

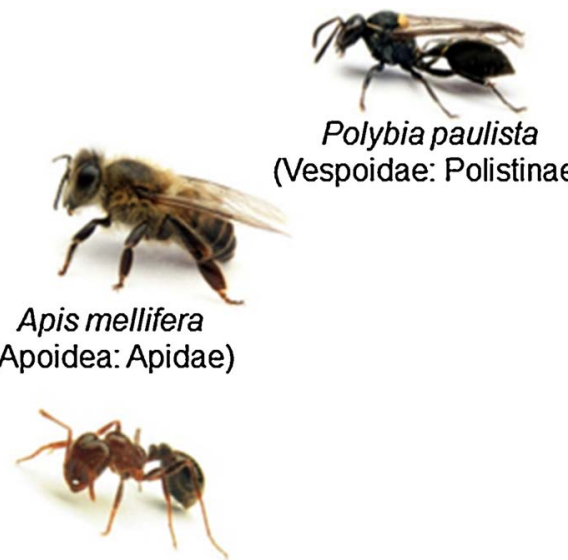

Solenopsis invicta (Scolioidea: Myrmicinae

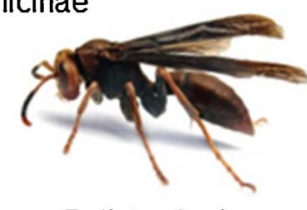

Polistes lanio

(Vespoidae: Polistinae)
Fig. 1. Clinically relevant species of social Hymenoptera from Brazil (Photos kindly provided by Professor M.S. Palma). 
Campinas, Sao Paulo State, Brazil). Two sera from non-sensitized healthy volunteers were used as negative controls. The study was approved by the Ethics Committee of FCM-UNICAMP under $n^{\circ} 187 / 2006$ (23rd July, 2006, updated in 2008). Informed consent was obtained in written form from all participants of the study.

\subsection{Insect venoms and allergens}

Nests from wasp species (P. paulista, P. ignobilis, $P$. scutellaris, $P$. lanio, A. pallens and A. pallipes) were captured around or within the campus of Universidade Estadual Paulista "Júlio de Mesquita Filho" (UNESP), Rio Claro, SP, Brazil (Licensed by Sisbio, No. 58500). A. mellifera individuals were obtained from colonies kept in the vivarium of UNESP's Rio Claro Institute of Biosciences. Venom extracts, native Poly p 1 and rPoly p 1 were obtained using previously described procedures (Perez-Riverol et al., 2016). PLA2 (Api m 1) and mellitin (Api m 4) were obtained commercially (Sigma, US). Venom extract from $S$. invicta was kindly provided by Prof. R.L. Zollner from the stock at the Laboratory of Translational Immunology (UNICAMP, Campinas, SP, Brazil). Venoms and PLA1s from P. dominula and $V$. vulgaris were provided by Euroimmun (Germany).

\subsection{Generation of monospecific sera by immunization}

Five Balb/c mice (female, 4 weeks old) were immunized intradermally with $20 \mu \mathrm{g}$ of rPoly p 1 in $\mathrm{PBS} / \mathrm{Al}(\mathrm{OH})_{3}$ in six weekly doses. Three mice were immunized with $20 \mu \mathrm{g}$ of solubilized proteins from $E$. coli BL21 (DE3) transformed with pET-28a vector for control purposes. A description of these protocols is given in the Supplementary Data.

\subsection{Immunoblotting and ELISA}

The sIgG and sIgE-mediated recognition of venoms and allergens by patients' sera and/or by sera from rPoly p 1-sensitized mice were assessed by immunoblotting and/or ELISA using protocols previously described (Perez-Riverol et al., 2016; Schiener et al., 2017). These protocols are provided in the Supplementary Data. The data analysis relied on Microsoft Excel, version 14.0 (Microsoft, US).

\subsection{Molecular modelling}

The 3-D models of PLA1s were generated by MODELLER (MartíRenom et al., 2000) using the structure of the venom PLA1 from Vespa basalis (PDB ID: 4QNN) as general template. The model was subjected to energy minimization using YASARA software (Krieger et al., 2009) and then validated using MolProbity (Chen et al., 2010) The ribbon diagram was prepared with PyMOL using the homology models as input.

\section{Results}

\subsection{Recombinant Poly p 1- mediated sensitization of mice}

The capability of rPoly p 1 to induce in vivo sensitization of mice $(n=5)$ after intradermal immunization was evaluated by immunoblotting. Detection of sIgE showed that allergen-specific reactivity with nPoly p 1 (Fig. 2a) and with P. paulista venom (Fig. 2b). A unique band corresponding to the predicted molecular weight of Poly $\mathrm{p} 1$ $(\sim 34 \mathrm{kDa})$ was obtained in immunoblotting with purified nPoly $\mathrm{p} 1$ and with the positive control (rPoly p 1) (Fig. 2a, d). For the crude venom, a second and less intense band $(\sim 25 \mathrm{kDa})$ was observed (Fig. 2b). The absence of detection for purified native Poly p 5 ( $50 \mu \mathrm{g})$ (Fig. 2c) which has a similar molecular weight (dos Santos-Pinto et al., 2014) suggests that the band corresponds to one of the multiple form of Poly p 1 identified in P. paulista (dos Santos et al., 2011) or a degradation product present in the venom.

\subsection{Cross-reactivity of sera from rPoly $p$ 1-sensitized mice}

Relevant non-vespid Hymenoptera species in Neotropical regions mainly are honeybee and fire ant. Assessing the sera from rPoly p 1sensitized mice in immunoblotting, we did not observe any cross-reactivity with neither HBV allergens (Api m 1, Api m 4) nor crude venom extract (Fig. 3a). Similarly, no reactivity was detected with crude venom of $S$. invicta (Fig. 3b). ELISA analyses for detection of cross-reactive sIgE/sIgG to these venoms further corroborated the lack of crossreactivity (Fig. 5).

Assessment of cross-reactivity to venoms of clinically relevant wasps from Neotropical (Fig. 4a) and temperate regions (Fig. 4b) was performed by detection of IgE and IgG. Notably, IgE as well as IgG reactivity could be detected for all venoms from Neotropical wasps and $P$. dominula, a clinically relevant wasp from Northern Hemisphere. The highest levels of cross-reactivity were obtained with venoms of the taxonomically more related species $P$. scutellaris and $P$. ignobilis. A pronounced reactivity was also detected for venoms from Neotropical species of different genera such as $P$. lanio, A. pallipes, A. pallens and with the venom from $P$. dominula (Fig. 4 b). No reaction however was detected with $V$. vulgaris venom, the most relevant wasp in Europe.

ELISA analyses supported the cross-reactivity among venoms from wasps of Neotropical and temperate regions (Fig. 5, Supplementary data Figs. 3 and 4) using Poly p 1-specific sera. For both IgE and IgG the results were similar to those obtained in the immunoblotting with higher reactivities of the more closely related Polybia species, $P$. scutellaris and $P$. ignobilis. Interestingly, high levels of cross-reactivity were also detected for Polistes venoms, with $P$. dominula showing a slightly higher signal than $P$. lanio among all individual serum (Supplemantary Data, Figs. 3 and 4). Similar to the immublotting analysis, no crossreactivity was detected with $A$. mellifera, $S$. invicta, $V$. vulgaris venoms and rVes v 1. Against the lack of CCDs (Seismann et al., 2010b), the PLA1-based cross-reactivity indicates the presence of common protein epitopes among the different variants of the allergen in the venoms evaluated here. In order to address the molecular basis of cross-reactivity we analyzed the identity of the primary sequence and structural similarity based on 3-D models of venom PLA1s for those of which the information is available.

Lacking crystallographic data for the PLA1s, the 3-D models of rPoly p 1 (GenBank ID: ADT89774.1), nPoly p 1 (A2VBC4.1), Pol d 1 (AAS67041.1), Ves v 1 (AAB48072.1) and Sol i 1 (NP_001291510) were built using the deposited pdb (PDB ID: 4QNN) of the PLA1 atomic coordinates from the hornet Vespula basalis. The lack of sequence information for PLA1s from $P$. scutellaris, $P$. ignobilis, $P$. lanio, $A$. pallipes and $A$. pallens hampers similar structural evaluations. The identity of the rPoly p 1 primary sequence with these PLA1s ranged from 36\% (Sol i 1) to $74 \%$ (Pol d 1) (Fig. 6). Meanwhile, in the structural analysis the root-mean square deviation (RMSD) of the atomic positions of the 3-D models varied from 0.172-0.083, with Sol i 1 and Pol d 1 showing the lowest and highest identity, respectively. The results from the sequences alignment (Perez-Riverol et al., 2016) and the overlay of the 3D models (Fig. 6) support the cross-reactivity observed in immunoblotting and ELISA. Higher values of sequence identity and structural similarity are associated with stronger IgE and IgG-mediated recognition of the PLA1s in the insect venoms. The results of different approaches are summarized in Table 1.

\subsection{Cross-reactivity of sera from allergic patients}

To reassess the potential of rPoly p 1 to differentiate double sensitization to wasp/bee or wasp/fire ant venoms from cross-reactivity, we evaluated the recognition of rPoly p 1 (Fig. 7) by sera from patients sensitized solely to HBV (12), fire ants (4) or P. paulista venom. Notably, none of the sera with SIgE to HBV showed cross-reactivity with rPoly $p$ 1. In contrast, all sera of patients sensitized to PPV recognized the rPoly p 1 . In summary, these data clearly suggest that the limited cross- 


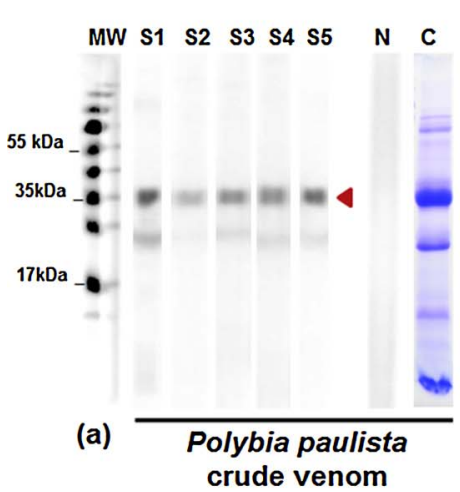

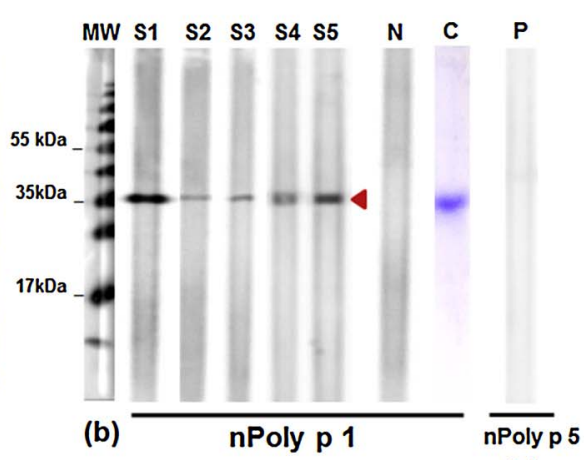

(c)

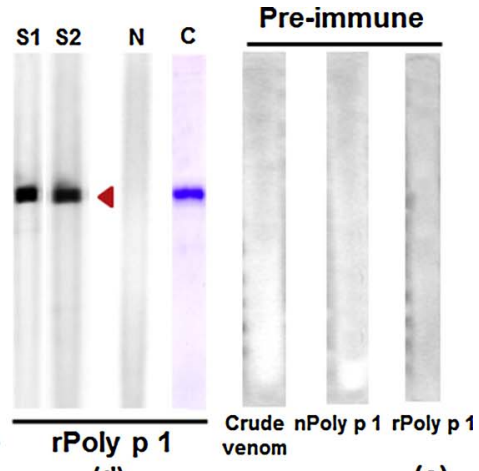

(d)

(e)

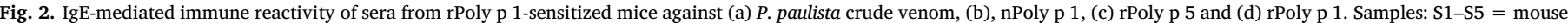

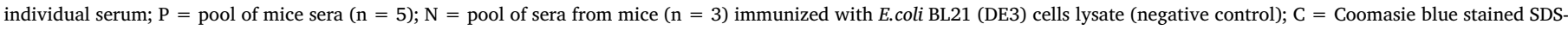

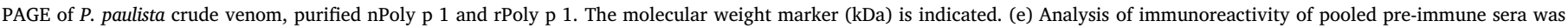
performed using venom, nPoly $\mathrm{p} 1$ and rPoly $\mathrm{p} 1$ as before.
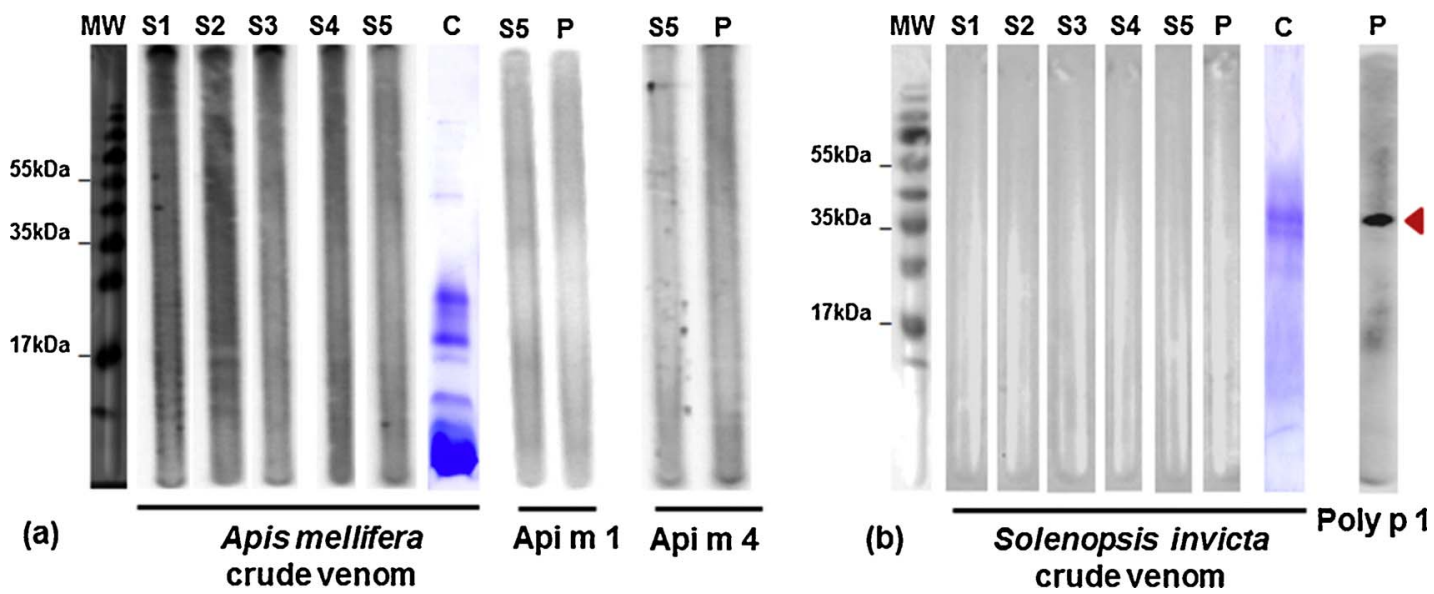

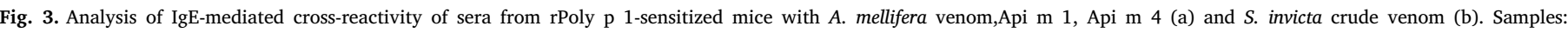

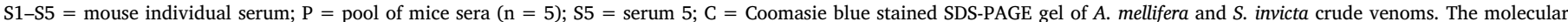
weight marker $(\mathrm{kDa})$ is indicated.
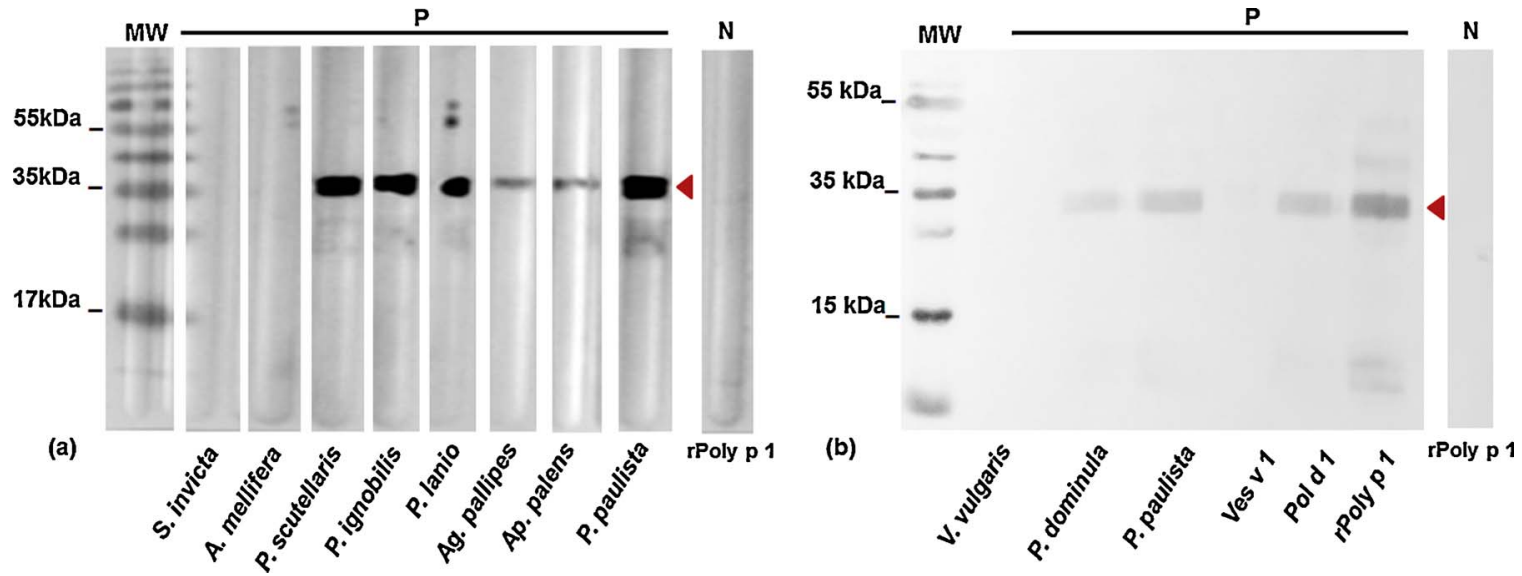

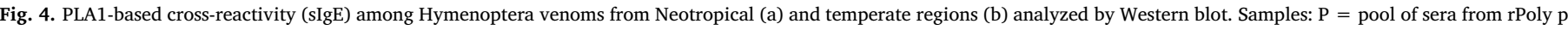

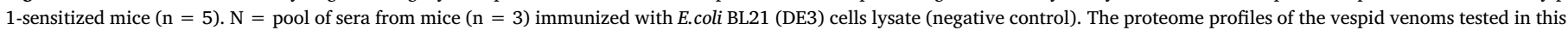
study are shown in the Supplementary data, Fig. 2.

reactivity of the PLA1 from $P$. paulista with PLAs from HBV and ant venom renders rPol p 1 a marker allergen for differentiation of sensitization to HBV and ant venom from venom of Neotropical wasps.

\section{Discussion}

Identification of the primary sensitizing insect is hampered by molecular cross-reactivity associated to the presence of CCDs (Brehler et al., 2013; Seismann et al., 2010a) and common epitopes from homologous allergens such as hyaluronidases (Jin et al., 2010), dipeptidylpeptidases (Blank et al., 2010) and vitellogenins (Blank et al., 2013). Differentiation of hymenoptera belonging to the same family, e.g. Vespula and Polistes species, demands even more refined analysis and knowledge on the molecular characteristics of venom allergens. 

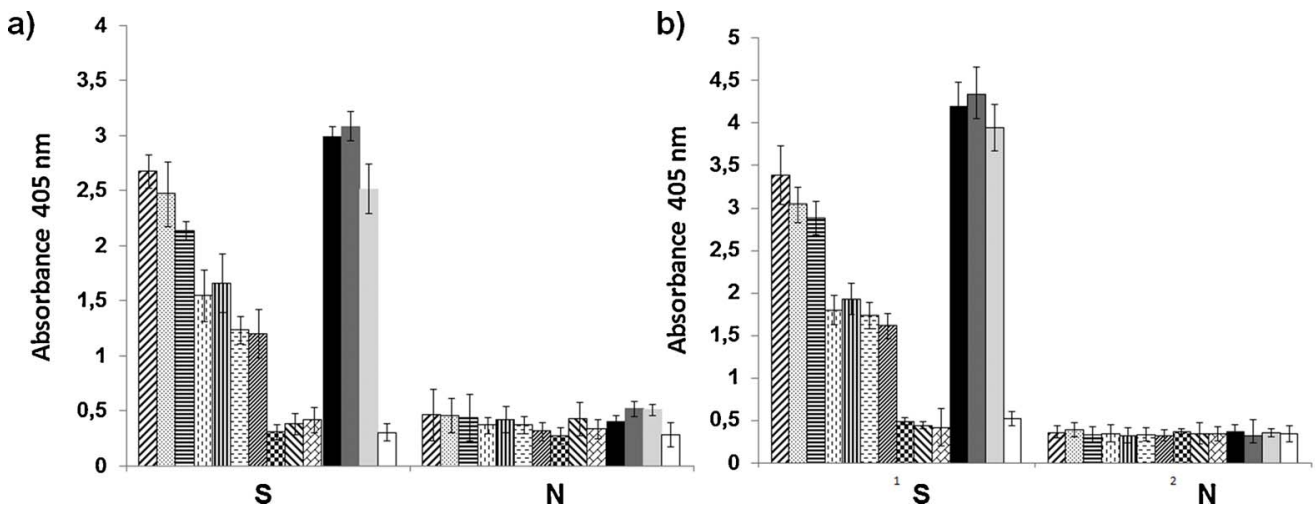

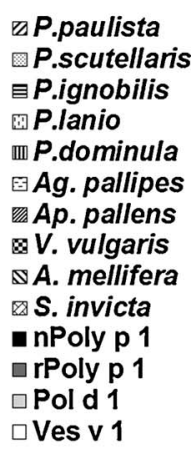

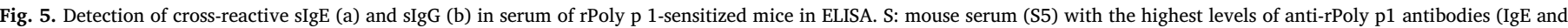

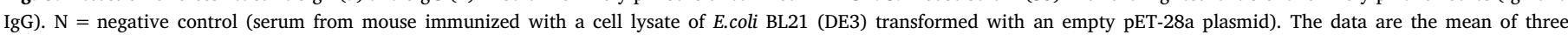
experimental replicates.

Wasp venom PLA1s are often non-glycosylated and therefore CCDlacking major allergens without homologues in HBV (Seismann et al., $2010 \mathrm{~b})$. These features render this group of allergens a feasible marker for differentiation of wasp and HBV allergy and a candidate for analysis of sensitization to different vespid species. However, little is known about the PLA1-based cross-reactivity among clinically relevant wasps or ants.

In this study, we performed a comprehensive analysis of the insect venom PLA1s-based cross-reactivity among venoms from insects of Neotropical and temperate regions. To address the insect venom PLA1based cross-reactivity with a molecularly well defined and highly specific tool, we immunized mice with rPoly $\mathrm{p} 1$. The recognition of nPoly p 1 by these sera indicates that the recombinant protein retains the relevant B-cell epitopes from the native form of the allergen. The presence of a second band in immunoblotting might be related to the recognition of a less predominant isoform of the PLA1 at $\sim 25 \mathrm{kDa}$ (dos Santos et al., 2011, 2010)., but proof needs to be provided.

Notably, sera of rPoly p1-sensitized mice did not show cross-reactivity with honeybee venom (and selected HBV allergens) and fire ant venom. These findings support previous results indicating that venom PLA1s are reliable markers for differentiation of wasp or HBV sensitizations (Korošec et al., 2012; Müller et al., 2012; Seismann et al., 2010b).

Immunoblotting and ELISA analyses independently revealed that
Table 1

Summary of the results obtained for PLA1s from venoms of clinically relevant wasps.

\begin{tabular}{|c|c|c|c|c|}
\hline \multicolumn{5}{|l|}{ rPoly p 1} \\
\hline Vespid PLA1s & $\begin{array}{l}\text { Sequence } \\
\text { identity }\end{array}$ & RMSD & $\begin{array}{l}\text { Relative intensity on } \\
\text { immublotting } \\
\text { reaction }\end{array}$ & $\begin{array}{l}\text { ELISA } \\
\left(\mathrm{OD}_{405} \mathrm{~nm}\right)^{\mathrm{a}}\end{array}$ \\
\hline P. paulista & $71 \%$ & 0.080 & +++ & 2.55 \\
\hline P. scutellaris & n.a & & +++ & 2.41 \\
\hline P.ignobilis & n.a & & +++ & 2.24 \\
\hline P. lanio & n.a & & ++ & 1.53 \\
\hline $\begin{array}{l}\text { P.dominula (Pol } \\
\quad \text { d 1) }\end{array}$ & $74 \%$ & 0.083 & ++ & 1.79 \\
\hline A. pallipes & n.a & & + & 1.20 \\
\hline A. pallens & n.a & & + & 1.17 \\
\hline $\begin{array}{l}\text { V. vulgaris (Ves } \\
\text { v } 1 \text { ) }\end{array}$ & $54 \%$ & 0.123 & - & 0.65 \\
\hline $\begin{array}{l}\text { S. invicta (Sol i } \\
\text { 1) }\end{array}$ & $36 \%$ & 0.172 & - & 0.44 \\
\hline A. mellifera & $\begin{array}{l}\text { no venom } \\
\text { PLA1 }\end{array}$ & & - & 0.39 \\
\hline
\end{tabular}

n.a: no available in nucleotide/protein databases.

- : negative.

a Data from the mouse serum with the highest sIgE levels to rPoly p 1.
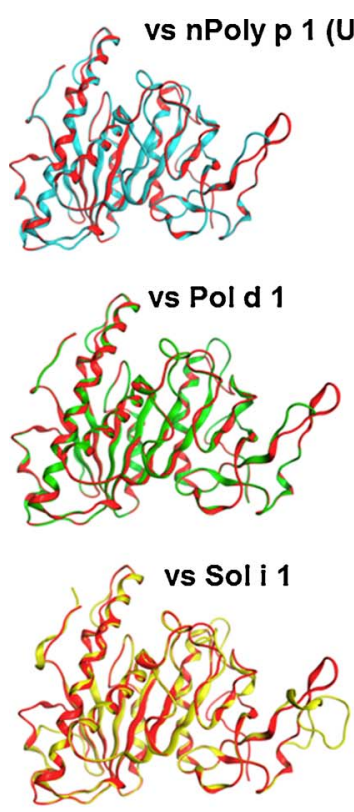

1 (Uniprot A2VBC4)
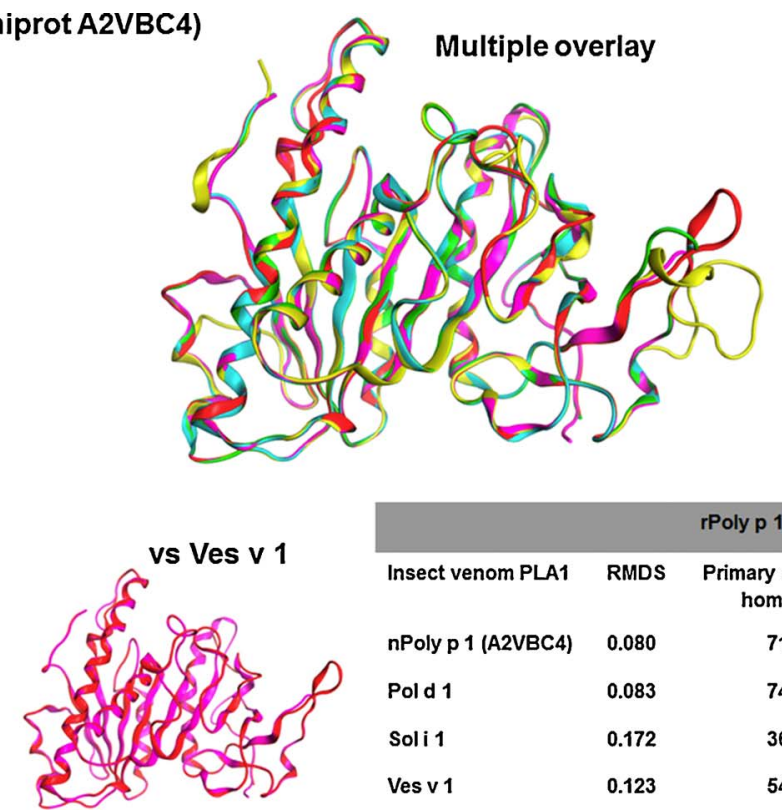

\begin{tabular}{|c|c|c|}
\hline & & rPoly p 1 \\
\hline Insect venom PLA1 & RMDS & $\begin{array}{c}\text { Primary sequence } \\
\text { homology }\end{array}$ \\
\hline nPoly p 1 (A2VBC4) & 0.080 & $71 \%$ \\
\hline Pold 1 & 0.083 & $74 \%$ \\
\hline Soli 1 & 0.172 & $36 \%$ \\
\hline Ves v 1 & 0.123 & $54 \%$ \\
\hline
\end{tabular}

Fig. 6. Overlay of the 3-D models of selected venom PLA1s with the model of rPoly $p$ 1. Samples: rPoly $p$ 1 (red), nPol y p 1 (Uniprot A2VBC4): variant of the native Poly p 1(Santos et al., 2007) (blue), Pol d 1 (green), Sol i 1 (yellow), Ves v 1 (purple). The primary sequence identity and RMSD of atomic positions of the 3-D models from the venom PLA1s compared to rPoly p 1 is shown. (For interpretation of the references to colour in this figure legend, the reader is referred to the web version of this article.) 


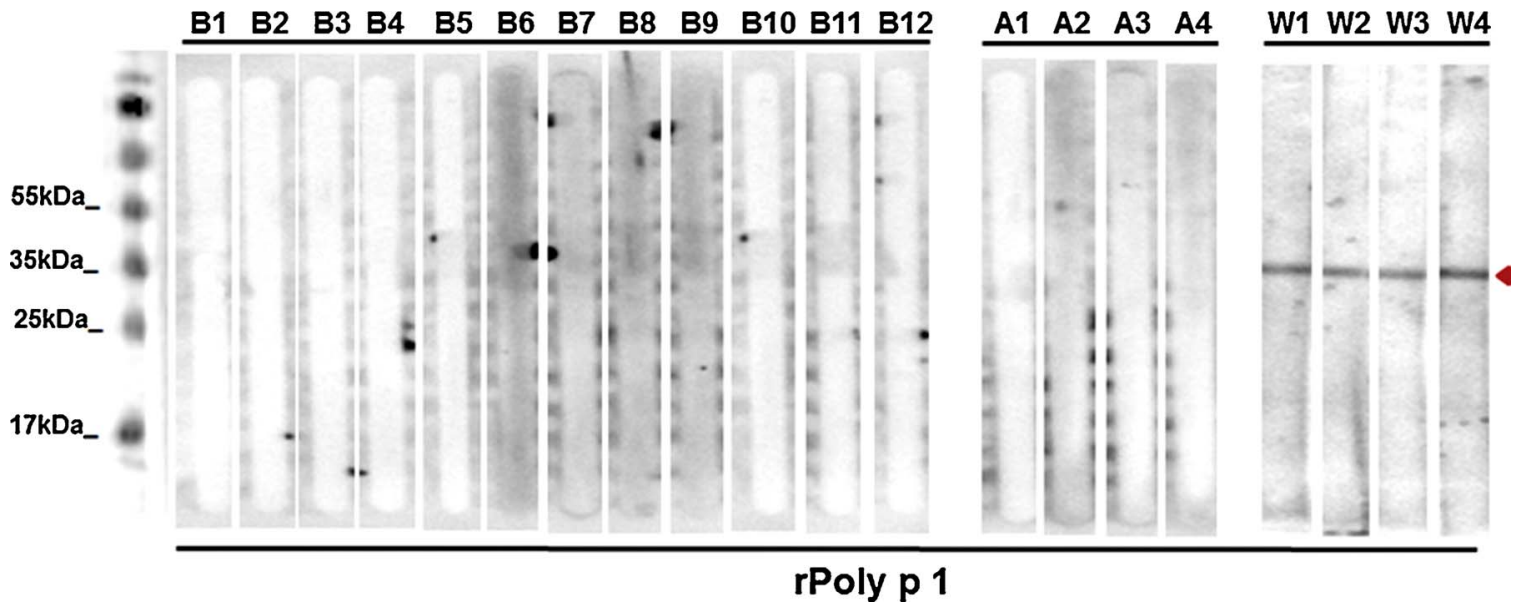

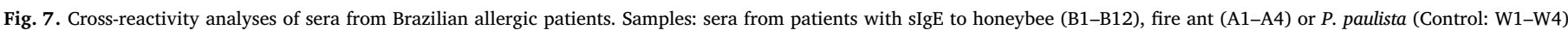
venoms. The molecular weight marker $(\mathrm{kDa})$ is indicated.

the levels of cross-reactivity among the venom PLA1s from insects of Neotropical zones and with species of temperate regions correlates with the similarity of the primary and 3-D structures. While in HBV a PLA1 has not been identified, Sol i 1 and Ves v 1 showed the lowest values of structural identity with Poly $\mathrm{p} 1$. These findings corroborate the absence of recognition by the sera. Interestingly, cross-reactivity between Ves v 1 and Pol d 1 from $P$. dominula has been reported (Monsalve et al., 2012) indicating molecular similarity between Vespula and Polistes species. It is important to mention that Polistes and Polybia species belong to the sub-family of Polistinae (Müller, 2010; Perez-Riverol et al., 2017). Hence, the high level of identity for Pol d 1 was associated with a high cross-reactivity. Unfortunately, sequence data for venom PLA1s from other Neotropical species tested is currently not available.

Several venom PLA1s from species of the genus Vespula showed up to $95 \%$ of homology (Monsalve et al., 2012). The extensive cross-reactivity obtained for Polybia species is likely to be due to high levels of identity on primary sequences and 3-D structures. For P. scutellaris, it has been shown that the sequence of antigen 5 (Poly s 5 ) has a $99 \%$ of identity with it counterpart in P. paulista venom (Vinzón et al., 2012, 2010). A similar situation might be true for PLA1 from P. scutellaris and $P$. ignobilis. The alignment of the primary sequence and 3-D model of the venom PLA1 from $P$. dominula, which is the major European counterpart of the Neotropical wasp $P$. lanio showed a high identity with Poly $\mathrm{p} 1$. Interestingly, the levels of cross-reactivity were similar for $P$. dominula and its Brazilian counterpart, suggesting that venom PLA1 from $P$. lanio could also have high levels of identity with Poly $\mathrm{p} 1$, and retains the homologues IgE-epitopes present in Poly $\mathrm{p} 1$ and Pol $\mathrm{d} 1$. Notably, the identities of Poly p 1 with Pol d 1 and the $P$. annularis PLA1, Pol a 1, are 74\% and 71\% (Perez-Riverol et al., 2016), respectively. In addition, there seems to be cross-reactivity between the PLA1s from European and North American Polistes species. This data suggests a similar level of cross-reactivity between rPoly p 1 and Pol a 1 .

Our results showed that vespid PLA1s are promising tools to differentiate wasp/bee and wasp/ant allergy. In contrast, the use of PLA1s for identifying the culprit wasp species is limited by protein-based cross-reactivity. Quantitative assays, however, could provide sIgE levels to different PLA1s and an immanent measure to rank the probability of culprit species. First attempts to differentiate Polistes and Vespula sensitization suggest a feasibility of comparative sIgE determinations (Monsalve et al., 2012).

Diagnosis based on venom extracts is common practice in Latin America and often causative for misidentification of the culprit insect. However, when assessing the IgE reactivity of Brazilian patients sera monosensitized to HBV and ant venom (negative on YJV) with rPoly $p$ 1 , we did not observe any cross-reactivity. These results emphasize that rPoly p 1 represents a feasible marker for differentiation of wasp sensitization from cross-reactivity with bee and ant venoms in Brazilian patients. Future studies involving a large number of sera are required to verify these initial results. Cellular analyses such as basophil activation tests (Balzer et al., 2014) might further broaden the potential for rPoly p 1- and PLA1-based molecular diagnostics for Neotropical HVA.

\section{Acknowledgments}

We acknowledge the financial support from FAPESP (São Paulo Research Foundation), (Grant numbers: 2006/54799-6, 2014/13936-7 and 2011/51684-1) and from FUNDUNESP-UNESP (Grant number: 01197/10-DFP). The authors thank CAPES-DS (Coordenação de Aperfeiçoamento de Pessoal de Nível Superior), Postgraduate Program of Biological Sciences (Cellular and Molecular Biology) at UNESP, Rio Claro, and CAPES-PDSE (Grant number 88881.132448/2016-01) for providing a doctoral scholarship to A.P.R and to FAPESP (Grant Number 2013/26451-9) for providing a Post-Doctoral scholarship to R.A.d S.P. This work was also supported by Council of Technological and Scientific Development (CNPq) - Brazil (grant no. 455422/20141).

\section{Appendix A. Supplementary data}

Supplementary data associated with this article can be found, in the online version, at http://dx.doi.org/10.1016/j.molimm.2017.11.007.

\section{References}

Balzer, L., Pennino, D., Blank, S., Seismann, H., Darsow, U., Schnedler, M., McIntyre, M., Ollert, M.W., Durham, S.R., Spillner, E., Ring, J., Cifuentes, L., 2014. Basophil activation test using recombinant allergens: highly specific diagnostic method complementing routine tests in wasp venom allergy. PLoS One 9. http://dx.doi.org/10. 1371/journal.pone.0108619.

Bazon, M.L., 2017. Expressão heteróloga, purificação e análise da imunoreatividade do alérgeno antígeno 5 do veneno de Polybia paulista (Hymenoptera, Vespidae).

Bilò, M.B., 2011. Anaphylaxis caused by Hymenoptera stings: from epidemiology to treatment. Allergy: Eur. J. Allergy Clin. Immunol. 66, 35-37. http://dx.doi.org/10. 1111/j.1398-9995.2011.02630.x.

Biló, B.M., Rueff, F., Mosbech, H., Bonifazi, F., Oude-Elberink, J.N.G., Birnbaum, J. Bucher, C., Forster, J., Hemmer, W., Incorvaia, C., Kontou-Fili, K., Gawlik, R., Muller, U., Fernandez, J., Jarish, R., Jutel, M., Wuthrich, B., 2005. Diagnosis of Hymenoptera venom allergy. Allergy: Eur. J. Allergy Clin. Immunol. 60, 1339-1349. http://dx.doi. org/10.1111/j.1398-9995.2005.00963.x.

Blank, S., Seismann, H., Bockisch, B., Braren, I., Cifuentes, L., McIntyre, M., Rühl, D., Ring, J., Bredehorst, R., Ollert, M.W., Grunwald, T., Spillner, E., 2010. Identification, recombinant expression, and characterization of the $100 \mathrm{kDa}$ high molecular weight Hymenoptera venom allergens Api m 5 and Ves v 3. J. Immunol. (Baltimore, Md.: 1950) 184, 5403-5413. http://dx.doi.org/10.4049/jimmunol.0803709.

Blank, S., Seismann, H., Mcintyre, M., Ollert, M., Wolf, S., Bantleon, F.I., Spillner, E. 2013. Vitellogenins are new high molecular weight components and allergens (Api m 12 and Ves v 6) of Apis mellifera and Vespula vulgaris venom. PLoS One 8. http://dx. 
doi.org/10.1371/journal.pone.0062009.

Brehler, R., Grundmann, S., Stocker, B., 2013. Cross-reacting carbohydrate determinants and hymenoptera venom allergy. Curr. Opin. Allergy Clin. Immunol. 13, 360-364. http://dx.doi.org/10.1097/ACI.0b013e328362c544.

Caruso, B., Bonadonna, P., Severino, M.G., Manfredi, M., Dama, A., Schiappoli, M., Rizzotti, P., Senna, G., Passalacqua, G., 2007. Evaluation of the IgE cross-reactions among vespid venoms. A possible approach for the choice of immunotherapy. Allergy $62,561-564$.

Chen, V.B., Arendall, W.B., Headd, J.J., Keedy, D.A., Immormino, R.M., Kapral, G.J., Murray, L.W., Richardson, J.S., Richardson, D.C., 2010. MolProbity: all-atom structure validation for macromolecular crystallography. Acta Crystallogr. Sect. D: Biol. Crystallogr. 66, 12-21.

dos Santos, L.D., Santos, K.S., dos Santos Pinto, J.R.A., Dias, N.B., De Souza, B.M., Dos Santos, M.F., Perales, J., Domont, G.B., Castro, F.M., Kalil, J.E., Palma, M.S., 2010. Profiling the proteome of the venom from the social wasp Polybia paulista: a clue to understand the envenoming mechanism. J. Proteome Res. 9, 3867-3877. http://dx. doi.org/10.1021/pr1000829.

dos Santos, L.D., da Silva Menegasso, A.R., dos Santos Pinto, J.R.A., Santos, K.S., Castro, F.M., Kalil, J.E., Palma, M.S., 2011. Proteomic characterization of the multiple forms of the PLAs from the venom of the social wasp Polybia paulista. Protein Pept. Lett. 11, 1403-1412. http://dx.doi.org/10.1002/pmic.201000414.

dos Santos-Pinto, J.R.A., dos Santos, L.D., Andrade Arcuri, H., Castro, F.M., Kalil, J.E., Palma, M.S., 2014. Using proteomic strategies for sequencing and post-translational modifications assignment of antigen-5, a major allergen from the venom of the social wasp Polybia paulista. J. Proteome Res. 13, 855-865. http://dx.doi.org/10.1021/ pr4008927.

Ebo, D.G., Faber, M., Sabato, V., Leysen, J., Bridts, C.H., De Clerck, L.S., 2012 Component-resolved diagnosis of wasp (yellow jacket) venom allergy. Clin. Exp. Allergy 43, 255-261. http://dx.doi.org/10.1111/cea.12057.

Frick, M., Fischer, J., Helbling, A., Ruëff, F., Wieczorek, D., Ollert, M., Pftüzner, W., Müller, S., Huss-Marp, J., Dorn, B., Biedermann, T., Lidholm, J., Ruecker, G., Bantleon, F., Miehe, M., Spillner, E., Jakob, T., 2016. Predominant Api m 10 sensitization as risk factor for treatment failure in honey bee venom immunotherapy. $\mathrm{J}$. Allergy Clin. Immunol. 138http://dx.doi.org/10.1016/j.jaci.2016.04.024. 1663.e91671.e9.

Hoffman, D.R., 2008. Structural biology of allergens from stinging and biting insects Curr. Opin. Allergy Clin. Immunol. 8, 338-342. http://dx.doi.org/10.1097/ACI. 0b013e3283036a7d.

Jin, C., Focke, M., Léonard, R., Jarisch, R., Altmann, F., Hemmer, W., 2010. Reassessing the role of hyaluronidase in yellow jacket venom allergy. J. Allergy Clin. Immunol 125, 184-190.

Köhler, J., Blank, S., Müller, S., Bantleon, F., Frick, M., Huss-Marp, J., Lidholm, J., Spillner, E., Jakob, T., 2014. Component resolution reveals additional major allergens in patients with honeybee venom allergy. J. Allergy Clin. Immunol. 133, 1383-1389. http://dx.doi.org/10.1016/j.jaci.2013.10.060.

Korošec, P., Valenta, R., Mittermann, I., Čelesnik, N., Šilar, M., Zidarn, M., Košnik, M., 2012. High sensitivity of CAP-FEIA rVes v 5 and rVes $v 1$ for diagnosis of Vespula venom allergy. J. Allergy Clin. Immunol. 129, 1406-1408. http://dx.doi.org/10. 1016/j.jaci.2011.12.975

Krieger, E., Joo, K., Lee, J., Lee, J., Raman, S., Thompson, J., Tyka, M., Baker, D., Karplus, K., 2009. Improving physical realism, stereochemistry, and side-chain accuracy in homology modeling: four approaches that performed well in CASP8. Proteins: Struct. Funct. Bioinfo. 77, 114-122.

Locher, G.D.A., Togni, O.C., Silveira, O.T., Giannotti, E., 2014. The social wasp fauna of a Riparian forest in Southeastern Brazil (Hymenoptera, Vespidae). Sociobiology 61, 225-233. http://dx.doi.org/10.13102/sociobiology.v61i2.225-233.

Müller, U.R., Johansen, N., Petersen, A.B., Fromberg-Nielsen, J., Haeberli, G., 2009. Hymenoptera venom allergy: analysis of double positivity to honey bee and Vespula venom by estimation of IgE antibodies to species-specific major allergens Api $\mathrm{m} 1$ and Ves v5. Allergy: Eur. J. Allergy Clin. Immunol. 64, 543-548. http://dx.doi.org/10. 1111/j.1398-9995.2008.01794.x.

Müller, U., Schmid-Grendelmeier, P., Hausmann, O., Helbling, A., 2012. IgE to recombinant allergens Api $\mathrm{m}$ 1, Ves v 1, and Ves v 5 distinguish double sensitization from crossreaction in venom allergy. Allergy: Eur. J. Allergy Clin. Immunol. 67,
1069-1073. http://dx.doi.org/10.1111/j.1398-9995.2012.02847.x.

Müller, U.R., 2010. Insect venoms. Chem. Immunol. Allergy 95, 141-156. http://dx.doi. org/10.1159/000315948.

Martí-Renom, M.A., Stuart, A.C., Fiser, A., Sánchez, R., Melo, F., Šali, A., 2000. Comparative protein structure modeling of genes and genomes. Annu. Rev. Biophys. Biomol. Struct. 29, 291-325.

Monsalve, R.I., Vega, A., Marqués, L., Miranda, A., Fernández, J., Soriano, V., Cruz, S., Domínguez-Noche, C., Sánchez-Morillas, L., Armisen-Gil, M., Guspí, R., Barber, D. 2012. Component-resolved diagnosis of vespid venom-allergic individuals: phospholipases and antigen $5 \mathrm{~s}$ are necessary to identify Vespula or Polistes sensitization. Allergy: Eur. J. Allergy Clin. Immunol. 67, 528-536. http://dx.doi.org/10.1111/j. 1398-9995.2011.02781.x.

Ollert, M., Blank, S., 2015. Anaphylaxis to insect venom allergens: role of molecular diagnostics. Curr. Allergy Asthma Rep. 15. http://dx.doi.org/10.1007/s11882-0150527-z.

Oropeza, A.R., Bindslev-Jensen, C., Broesby-Olsen, S., Kristensen, T., Møller, M.B., Vestergaard, H., Kjaer, H.F., Halken, S., Lassen, A., Mortz, C.G., 2017. Patterns of anaphylaxis after diagnostic work-up: a follow-up study of 226 patients with suspected anaphylaxis. Allergy 0, 1-9. http://dx.doi.org/10.1111/all.13207.

Perez-Riverol, A., Justo-Jacomini, D.L., de Lima Zollner, R., Brochetto-Braga, M.R., 2015 Facing Hymenoptera venom allergy: from natural to recombinant allergens. Toxins 7 , 2551-2570. http://dx.doi.org/10.3390/toxins7072551.

Perez-Riverol, A., Campos Pereira, F.D., Musacchio Lasa, A., Romani Fernandes, L.G., dos Santos-Pinto, J.R.A., Justo-Jacomini, D.L., Oliveira de Azevedo, G., Bazon, M.L., Palma, M.S., de L. Zollner, R., Brochetto-Braga, M.R., 2016. Molecular cloning, expression and IgE-immunoreactivity of phospholipase A1, a major allergen from Polybia paulista (Hymenoptera: Vespidae) venom. Toxicon 124, 44-52. http://dx.doi. org/10.1016/j.toxicon.2016.11.006.

Perez-Riverol, A., dos Santos-Pinto, J.R.A., Lasa, A.M., Palma, M.S., Brochetto-Braga, M.R., 2017. Wasp venomic: unravelling the toxins arsenal of Polybia paulista venom and its potential pharmaceutical applications. J. Proteomics 161, 88-103. http://dx. doi.org/10.1016/j.jprot.2017.04.016.

Santos, L.D., Santos, K.S., de Souza, B.M., Arcuri, H.A., Cunha-Neto, E., Castro, F.M., Kalil, J.E., Palma, M.S., 2007. Purification, sequencing and structural characterization of the phospholipase A1 from the venom of the social wasp Polybia paulista (Hymenoptera, Vespidae). Toxicon 50, 923-937. http://dx.doi.org/10.1016/j. toxicon.2007.06.027.

Schiener, M., Eberlein, B., Moreno-Aguilar, C., Pietsch, G., Serrano, P., McIntyre, M., Schwarze, L., Russkamp, D., Biedermann, T., Spillner, E., Darsow, U., Ollert, M., Schmidt-Weber, C.B., Blank, S., 2017. Application of recombinant antigen 5 allergen from seven allergy-relevant Hymenoptera species in diagnostics. Allergy: Eur. J. Allergy Clin. Immunol. 72, 98-108. http://dx.doi.org/10.1111/all.13000.

Seismann, H., Blank, S., Braren, I., Greunke, K., Cifuentes, L., Grunwald, T., Bredehorst, R., Ollert, M., Spillner, E., 2010a. Dissecting cross-reactivity in hymenoptera venom allergy by circumvention of $\alpha-1,3$-core fucosylation. Mol. Immunol. 47, 799-808. http://dx.doi.org/10.1016/j.molimm.2009.10.005.

Seismann, H., Blank, S., Cifuentes, L., Braren, I., Bredehorst, R., Grunwald, T., Ollert, M., Spillner, E., 2010b. Recombinant phospholipase A1 (Ves v 1) from yellow jacket venom for improved diagnosis of hymenoptera venom hypersensitivity. Clin. Mol. Allergy 8, 7. http://dx.doi.org/10.1186/1476-7961-8-7.

Spillner, E., Blank, S., Jakob, T., 2014. Hymenoptera allergens: from venom to venome. Front. Immunol. 5, 1-7. http://dx.doi.org/10.3389/fimmu.2014.00077.

Sturm, G.J., Hemmer, W., Hawranek, T., Lang, R., Ollert, M., Spillner, E., Blank, S., Bokanovic, D., Aberer, W., 2010. Detection of IgE to recombinant Api $\mathrm{m} 1$ and rVes v 5 is valuable but not sufficient to distinguish bee from wasp venom allergy. J. Allergy Clin. Immunol. 128, 247-248. http://dx.doi.org/10.1016/j.jaci.2011.02.021.

Vinzón, S.E., Pirpignani, M.L., Nowicki, C., De Jimènez Bonino, M.B., 2010. Molecular cloning and expression in Pichia pastoris of a hypoallergenic antigen 5. Protein Expr. Purif. 73, 23-30. http://dx.doi.org/10.1016/j.pep.2010.03.029.

Vinzón, S.E., Marino-Buslje, C., Rivera, E., Biscoglio de Jiménez Bonino, M., 2012. A naturally occurring hypoallergenic variant of vespid antigen 5 from Polybia scutellaris venom as a candidate for allergen-specific immunotherapy. PLoS One 7. http://dx. doi.org/10.1371/journal.pone.0041351. 